\title{
Roman Urba
}

Instytut Nafty i Gazu - Państwowy Instytut Badawczy

\section{Zastosowanie narzędzi programistycznych do oceny hałasu wokół eksploatowanych wiertnic}

\begin{abstract}
Wierceniu otworów w górnictwie naftowym towarzyszy emisja hałasu mechanicznego i hałasu aerodynamicznego wytwarzanego przez urządzenia wiertnicze. Biorąc pod uwagę postęp techniczny i zastosowanie środków zmniejszających hałas w projektowaniu urządzeń wiertniczych, zagrożenia wynikające z emisji hałasu powinny być zmniejszane w szczególności u źródła. W artykule przedstawiono rozkład poziomu hałasu w środowisku otaczającym urządzenie wiertnicze. Wartości poziomu hałasu uzyskano poprzez pomiary wykonane według odpowiedniej procedury, a następnie porównano je z wartościami dopuszczalnymi. Opracowano arkusz kalkulacyjny do obliczeń poziomu hałasu występującego wokół urządzeń wiertniczych.
\end{abstract}

Słowa kluczowe: środowisko wiertni, hałas, arkusz kalkulacyjny.

\section{Use of programming tools for noise level evaluation around operating drilling rigs}

\begin{abstract}
The process of oil well drilling is usually accompanied by mechanical and aerodynamic noise created by drilling rigs. This publication presents noise distribution in the environment that surrounds drilling rigs. The values of noise levels were obtained by measurements performed according to appropriate procedure and compared with permissible values. Taking into account technical advances and the use of noise reduction measures at the phase of drilling rig design, the menace resulting from noise emissions should be lowered, especially at the noise source. A spreadsheet was created for the calculation of noise existing around drilling rigs.
\end{abstract}

Key words: environment, noise, spreadsheet.

\section{Wprowadzenie}

Proces wykonywania otworu wiertniczego, na który składają się operacje wiercenia i zapuszczania kolumny przewodu wiertniczego oraz prace pomocnicze podzespołów urządzenia wiertniczego, pomp płuczkowych, agregatów i technicznych urządzeń pomocniczych, wywiera znaczny wpływ na kształtowanie się poziomu hałasu podczas wiercenia. Poziom hałasu zazwyczaj przekracza wartości dopuszczalne według przepisów i obowiązujących norm $[3,4,8]$, oddziałując niekorzystnie na otaczające środowisko wiertni. Emitowany hałas w czasie całodobowej pracy wiertnicy ma szczególne znaczenie w przypadku zlokalizowanej w bliskim sąsiedztwie zabudowy, zarówno zagrodowej, jak i mieszkaniowej. Emisja do środowiska hałasu wytwarza- nego przez eksploatowane typy urządzeń wiertniczych stanowi przedmiot zainteresowania Państwowej Inspekcji Sanitarnej oraz Ministerstwa Środowiska. Zgodnie z wymienionymi aktami prawnymi oraz wymogami Unii Europejskiej pracujące urządzenia wiertnicze w kraju lub za granicą winny posiadać udokumentowaną ocenę emisji hałasu do środowiska. Cel osiągnięto poprzez wykonanie pomiarów poziomu hałasu zgodnie $\mathrm{z}$ wymaganiami dyrektywy w tym zakresie [3]. Biorąc pod uwagę postęp techniczny i zastosowanie środków zmniejszających hałas w projektowaniu urządzeń wiertniczych, zagrożenia wynikające $\mathrm{z}$ energii hałasu powinny być zmniejszane w szczególności u źródła. 


\section{Badania poziomu hałasu w strefie otaczającej wiertnię}

W celu oceny i wyznaczenia stref bezpieczeństwa związanych z narażeniem na hałas podczas wiercenia otworu w zadanym czasie ekspozycji wykonano pomiary poziomu hałasu. Zastosowano miernik dźwięku klasy 1 - SVAN 958 z przedwzmacniaczem SV12L produkcji firmy SVANTEK, z mikrofonem SV22, który w trakcie pomiarów skierowany był w stronę źródła hałasu. Badania wykonano podczas wiercenia otworu wiertniczego. Do generowania przestrzennych rozkładów poziomu hałasu użyto metody geostatycznej analizy danych [2]. Zastosowano metodę krigingu bazującego na wartościach zmierzonych w punktach pomiarowych oraz parametrach przestrzennego rozkładu takich jak korelacja i wariancja, mając wygenerowaną mapę rozkładu poziomu hałasu w postaci wartości na siatce, w których poziom hałasu jest dopuszczalny lub przekroczony. Jakość wykonywanych pomiarów na urządzeniu wiertniczym w czasie operacji wiertniczych ma decydujące znaczenie dla analizy zagrożeń hałasem w miejscach pracy i przebywania pracowników. Na podstawie przeprowadzonych pomiarów na rysunku 1 przedstawiono poziom hałasu emitowanego do środowiska w strefie sąsiadujących budynków mieszkalnych. Pomiary wykonano zgodnie z rozporządzeniem Ministra Środowiska, dyrektywą 2002/49/WE oraz polskimi normami [3, 5-8]. Pracowały silniki pompowe typu CAT 3512 (2 szt.), silniki wyciągu wiertniczego typu CAT 3408 (2 szt.), silniki agregatów prądotwórczych typu CA3412 (2 szt.), pompy płuczkowe typu A850PT (2 szt.) oraz sita wibracyjne typu SVAKO. Wiatr wiał z prędkością $0,5 \div 1,0 \mathrm{~m} / \mathrm{s}$ z kierunku południowego, temperatura wynosiła $+30^{\circ} \mathrm{C}$, a ciśnienie atmosferyczne $990 \mathrm{hPa}$. Pomiary hałasu przeprowadzono podczas przerabiania otworu wiertniczego na głębokości $420 \div 454$ m oraz w czasie wiercenia otworu świdrem skrawającym typu PDC $\phi 311 \mathrm{~mm}$ na głębokości $553 \div 560 \mathrm{~m}$ na wiertni Parkosz-1K [1]. W tablicy 1 przedstawiono zmierzone wartości poziomów dźwięku w porze dnia. Na rysunku 2 pokazano mapę rozkładu poziomu hałasu [dBA] w otoczeniu wiertni podczas pracy urządzenia wiertniczego typu Kremco K-900. Pomiary wykonano na wiertni Parkosz-1K, zlokalizowanej w miejscowości Pilzno w powiecie dębickim w województwie podkarpackim, zarządzanej przez firmę Exalo Drilling S.A. Centrum Jasło. Przy budynku nr 1 poziom hałasu wynosi około $64,1 \mathrm{dBA}$, zaś przy budynku nr 2 równoważny poziom hałasu ma w przybliżeniu wartość 64,3 dBA podczas wiercenia otworu wiertniczego na głębokości około $553 \div 560 \mathrm{~m}$.

- Przy budynku mieszkalnym nr 1 wartość równoważnego poziomu dźwięku A wyrażonego wskaźnikiem $L_{A e g D}$ przekracza dopuszczalną wartość normy o $6,1 \mathrm{~dB}$.
- Przy budynku mieszkalnym nr 2 wartość równoważnego poziomu dźwięku A wyrażonego wskaźnikiem hałasu $L_{\text {AegD }}$ przekracza dopuszczalną wartość normy o $6,3 \mathrm{~dB}$. Współrzędne geograficzne otworu wiertniczego Parkosz-1K: $\mathrm{N}-49^{\circ} 59^{\prime} 54,64^{\prime \prime} ; \mathrm{E}-21^{\circ} 18^{\prime} 41,40^{\prime \prime}$.

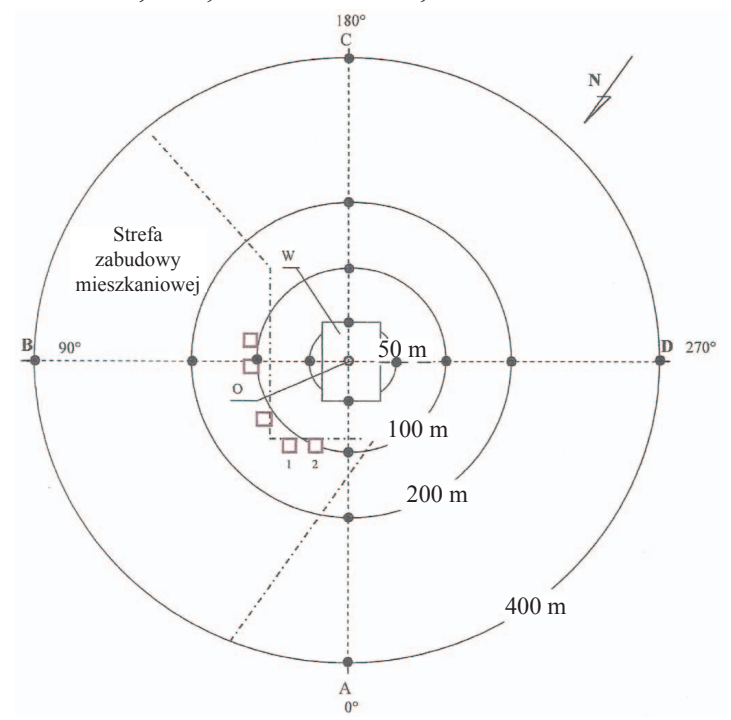

Rys. 1. Schemat rozmieszczenia punktów pomiarowych poziomu hałasu emitowanego do środowiska podczas pracy urządzenia wiertniczego typu Kremco K-900

- - punkt pomiarowy poziomu hałasu, O - otwór wiertniczy, $\mathrm{W}$ - teren wiertni, A - strona składowania przewodu wiertniczego (rampa rurowa), $\square$ - budynek mieszkalny

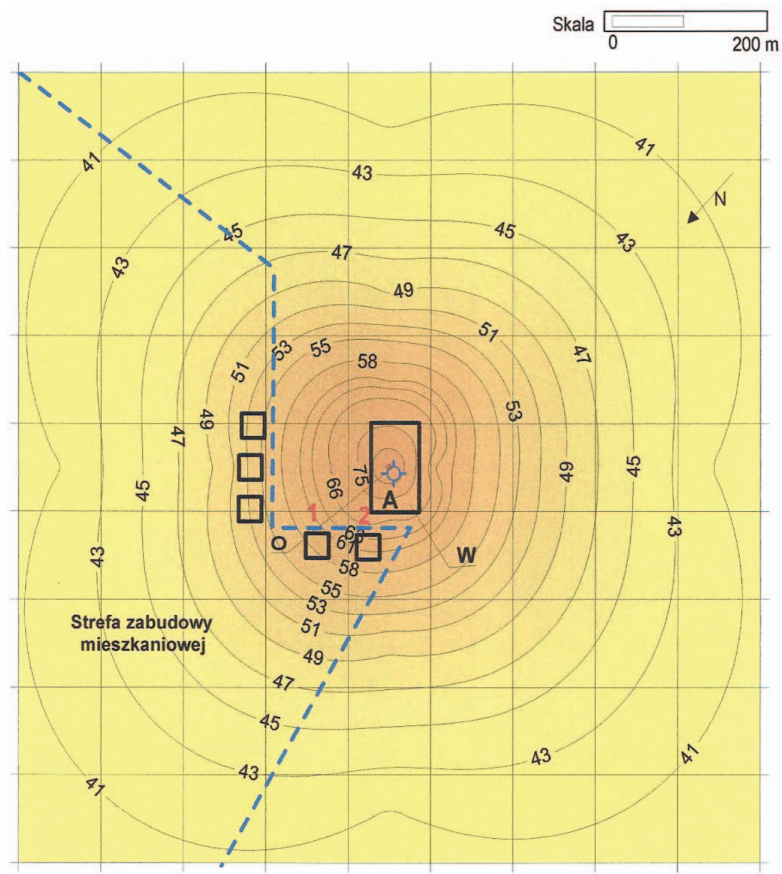

Rys. 2. Mapa rozkładu poziomu hałasu [dBA] emitowanego do środowiska podczas pracy urządzenia wiertniczego typu Kremco K-900 (wiercenie otworu - dzień)

$\mathrm{O}$ - otwór wiertniczy, $\mathrm{W}$ - teren wiertni, A - strona składowania przewodu wiertniczego (rampa rurowa) 


\section{NAFTA-GAZ}

Faza pracy urzadzenia wiertniczego - WIERCENIE

Parametry wiercenia: ciężar na haku: 36 T; obroty stołu: 85 obr./min; ciśnienie zatłaczania: 109 bar; liczba pracujących pomp: 2; nacisk na świder: $10 \mathrm{~T}$

Tablica 1. Zmierzone wartości poziomów dźwięku w porze dnia

\begin{tabular}{|c|c|c|c|c|c|c|}
\hline $\begin{array}{l}\text { Lokalizacja punktu } \\
\text { pomiarowego (kierunek } \\
\text { - odległość wg rys. 1) }\end{array}$ & $\begin{array}{c}\text { Zmierzony poziom } \\
\text { dźwięku (próbki) } \\
L_{A k}[\mathrm{dBA}]\end{array}$ & $\begin{array}{l}\text { Czas pomiaru } \\
\text { próbki } \\
t_{0}[\mathrm{~s}]\end{array}$ & $\begin{array}{c}\text { Średni poziom } \\
\text { dźwięku } \\
L_{A s s r}[\mathrm{dBA}]\end{array}$ & $\begin{array}{c}\text { Średni poziom } \\
\text { tła akustycznego } \\
L_{A t}[\mathrm{dBA}]\end{array}$ & $\begin{array}{c}\text { Poziom emisji } \\
\text { hałasu } \\
L_{A e k}[\mathrm{dBA}]\end{array}$ & $\begin{array}{c}\text { Czas pracy } \\
\text { (czas odniesienia) } \\
t[\mathrm{~h}]\end{array}$ \\
\hline A-50 & $\begin{array}{l}68,5 \\
68,1 \\
68,4\end{array}$ & 60 & 68,3 & \multirow{4}{*}{$31,0+1,0$} & $68,3+0,9$ & \multirow{4}{*}{ praca całodobowa } \\
\hline A-100 & $\begin{array}{l}60,2 \\
60,5 \\
60,3\end{array}$ & 60 & 60,3 & & $60,3+0,9$ & \\
\hline A-200 & $\begin{array}{l}50,0 \\
49,6 \\
49,7\end{array}$ & 60 & 49,8 & & $49,7+0,9$ & \\
\hline A-400 & $\begin{array}{l}41,0 \\
40,6 \\
40,5\end{array}$ & 60 & 40,7 & & $40,2+1,0$ & \\
\hline B-50 & $\begin{array}{l}69,7 \\
69,4 \\
69,5\end{array}$ & 60 & 69,5 & \multirow{4}{*}{$31,0+1,0$} & $69,5+0,9$ & \multirow{4}{*}{ praca całodobowa } \\
\hline B-100 & $\begin{array}{l}62,1 \\
62,4 \\
62,0\end{array}$ & 60 & 62,2 & & $62,2+0,9$ & \\
\hline B-200 & $\begin{array}{l}50,0 \\
49,8 \\
49,8\end{array}$ & 60 & 49,9 & & $49,8+0,9$ & \\
\hline B-400 & $\begin{array}{l}40,8 \\
41,0 \\
41,2\end{array}$ & 60 & 41,0 & & $40,6+1,0$ & \\
\hline C-50 & $\begin{array}{l}74,2 \\
74,0 \\
74,1\end{array}$ & 60 & 74,1 & \multirow{4}{*}{$31,0+1,0$} & $74,1+0,9$ & \multirow{4}{*}{ praca całodobowa } \\
\hline C-100 & $\begin{array}{l}60,8 \\
60,6 \\
60,7\end{array}$ & 60 & 60,7 & & $60,7+0,9$ & \\
\hline C-200 & $\begin{array}{l}48,8 \\
49,0 \\
48,9\end{array}$ & 60 & 48,9 & & $48,8+0,9$ & \\
\hline $\mathrm{C}-400$ & $\begin{array}{l}40,6 \\
40,8 \\
40,5\end{array}$ & 60 & 40,6 & & $40,1+0,9$ & \\
\hline D-50 & $\begin{array}{l}64,7 \\
64,8 \\
64,6 \\
\end{array}$ & 60 & 64,7 & \multirow{4}{*}{$31,0+1,0$} & $64,7+0,9$ & \multirow{4}{*}{ praca całodobowa } \\
\hline D-100 & $\begin{array}{l}58,2 \\
58,0 \\
58,3\end{array}$ & 60 & 58,2 & & $58,2+0,9$ & \\
\hline D-200 & $\begin{array}{l}50,0 \\
49,8 \\
49,7\end{array}$ & 60 & 49,8 & & $49,8+0,9$ & \\
\hline D-400 & $\begin{array}{l}41,0 \\
40,8 \\
40,7\end{array}$ & 60 & 40,8 & & $40,4+0,9$ & \\
\hline
\end{tabular}


Niepewność rozszerzona pomiaru została wyznaczona według PB-01/KA wyd. 1 z 25.03.2010 r. (przy poziomie ufności 95\% i $k=2$ ).
Uwagi: Pomiary poziomu hałasu rozpoczęto przy głębokości otworu $553 \mathrm{~m}$, a zakończono przy głębokości $561 \mathrm{~m}$. Przewiercany pokład - łupki, iłowce, mułowce.

\section{Arkusz kalkulacyjny do wyznaczania emisji hałasu w otoczeniu wiertni}

W celu usprawnienia obliczania parametrów oceny hałasu emitowanego do środowiska w strefie pracy wiertni opracowano arkusz kalkulacyjny. Przygotowany arkusz pozwala w prosty i szybki sposób wyliczyć podstawowe parametry oceny hałasu oraz oszacowania niepewności uzyskanych wyników. Wszystkie formuły zastosowane w algorytmach makra obliczeniowego arkusza są zgodne z aktualnie obowiązującymi normami: PN-N-01341:2000/Ap1:2001, PN-ISO 1996-1:2006 i PN-ISO 1996-2:1999/A1:2002.

Do pracy dołączono skoroszyt Hałas_KA_2015_A.xls, zawierający przykład obliczeniowy sporządzony na podstawie wykonanych pomiarów hałasu w obiekcie pomiarowym.

\section{Organizacja skoroszytu i edycja danych}

Opracowany skoroszyt zawiera następujące arkusze:

- „Opis” - arkusz z danymi zleceniodawcy, opisem obiektu pomiarowego, wykonywanych czynności i użytej aparatury pomiarowej.

- „Pomiar” - w górnej części arkusza znajdują się dane opisujące: liczbę punktów pomiarowych; poziom istotności $(\alpha)$ wyznaczenia wartości krytycznej szacowanych niepewności dla testu t-Studenta; numer punktu pomiarowego, w którym zmierzono tło hałasu; dokładność przyrządu pomiarowego, która będzie miarą niepewności typu B. W tablicy poniżej znajdują się informacje zawierające: opis punktów pomiarowych; liczbę wykonanych pomiarów w każdym punkcie; czasy pomiaru dla pojedynczej serii pomiarowej i czas odniesienia - dla każdego punktu pomiarowego. W kolejnych kolumnach znajdują się wyniki zmierzonych w danym punkcie pomiarowym wartości poziomu dźwięku serii pomiarowej (próbki).
W kolejnych kolumnach znajdują się wyliczone, dla każdego pomiaru, wartości ekspozycji względnej E.

- „Rozkład” - dodatkowy arkusz zawierający tabele z wartościami krytycznymi rozkładu t-Studenta.

Wszystkie formuły obliczeniowe wykonywane są za pomocą procedur zaimplementowanych w makrze o nazwie „Licz”. Makro to uruchamiane jest poprzez wybranie z klawiatury kombinacji klawiszy: $\mathrm{Ctrl}+\mathrm{m}$.

Co do kolorystyki arkuszy przyjęto następującą zasadę:

- tło komórek zawierających opisy oznaczono kolorem jasnoniebieskim lub rdzawym, a litery - granatowym;

- tło komórek zawierających opisy i dane pomiarowe oznaczono kolorem jasnozielonym, a litery - granatowym;

- tło komórek zawierających wyniki obliczeń oznaczono kolorem jasnoniebieskim, a litery - kolorem czerwonym. Dla przykładu obliczeniowego zamieszczono trzy skany arkuszy.

- „Wynik” - arkusz zawiera tabelę z wyliczonymi wartościami: średniego poziomu dźwięku $L_{A s r}[\mathrm{dBA}]$; poziomu emisji hałasu do środowiska $L_{\text {Aek }}[\mathrm{dBA}]$; niepewności typu A związanej z rozrzutem wyników pomiaru poniżej $\left(-\mathrm{U}_{\mathrm{A}, 95}\right)$ i powyżej $\left(+\mathrm{U}_{\mathrm{A}, 95}\right)$ poziomu emisji hałasu do środowiska; niepewności rozszerzonej, uwzględniającej niepewność typu A i założoną niepewność typu $\mathrm{B}$, związanej z rozrzutem wyników pomiaru poniżej $\left(-\mathrm{U}_{\mathrm{R}, 95}\right)$ i powyżej $\left(+\mathrm{U}_{\mathrm{R}, 95}\right)$ poziomu emisji hałasu do środowiska.

\begin{tabular}{|c|c|}
\hline \multicolumn{2}{|l|}{ Arkusz ,Opis" } \\
\hline \multicolumn{2}{|c|}{ DANE ZLECENIODAWCY I INFORMACJE O OBIEKCIE POMIAROWYM } \\
\hline Nazwa zleceniodawcy & PNiG Jasło Oddział NAFTA-GAZ w Wołominie \\
\hline Adres & ul. Łukasiewicza 14, 05-200 Wołomin \\
\hline Wydział & Wiertnia Bogdaj Uciechów 45 \\
\hline \multicolumn{2}{|l|}{ Lokalizacja } \\
\hline Nazwa obiektu pomiarowego & Wiertnia Pakosz-1K \\
\hline \multirow[t]{5}{*}{ Pracujące urzadzenia } & Silniki pompowe typu CAT 3512 (2 szt.) \\
\hline & Silniki wyciągu wiertniczego typ CAT 3408 (2 szt.) \\
\hline & Silniki agregatów prądotwórczych typ CAT 3412 (2 szt.) \\
\hline & Pompy płuczkowe typ A850T (2 szt.) \\
\hline & Sita wibracyjne typ SVACO \\
\hline Warunki pracy urządzenia & Wiercenie otworu świdrem skrawającym typ PDC 311 \\
\hline \multicolumn{2}{|c|}{ DANE O UŻYTEJ APARATURZE POMIAROWEJ } \\
\hline \multirow[t]{3}{*}{ Użyta aparatura pomiarowa } & Miernik dźwięku SVAN 958 \\
\hline & Przedwzmacniacz typ SV12L \\
\hline & Mikrofon typ SV22 \\
\hline
\end{tabular}


Arkusz ,Pomiar"

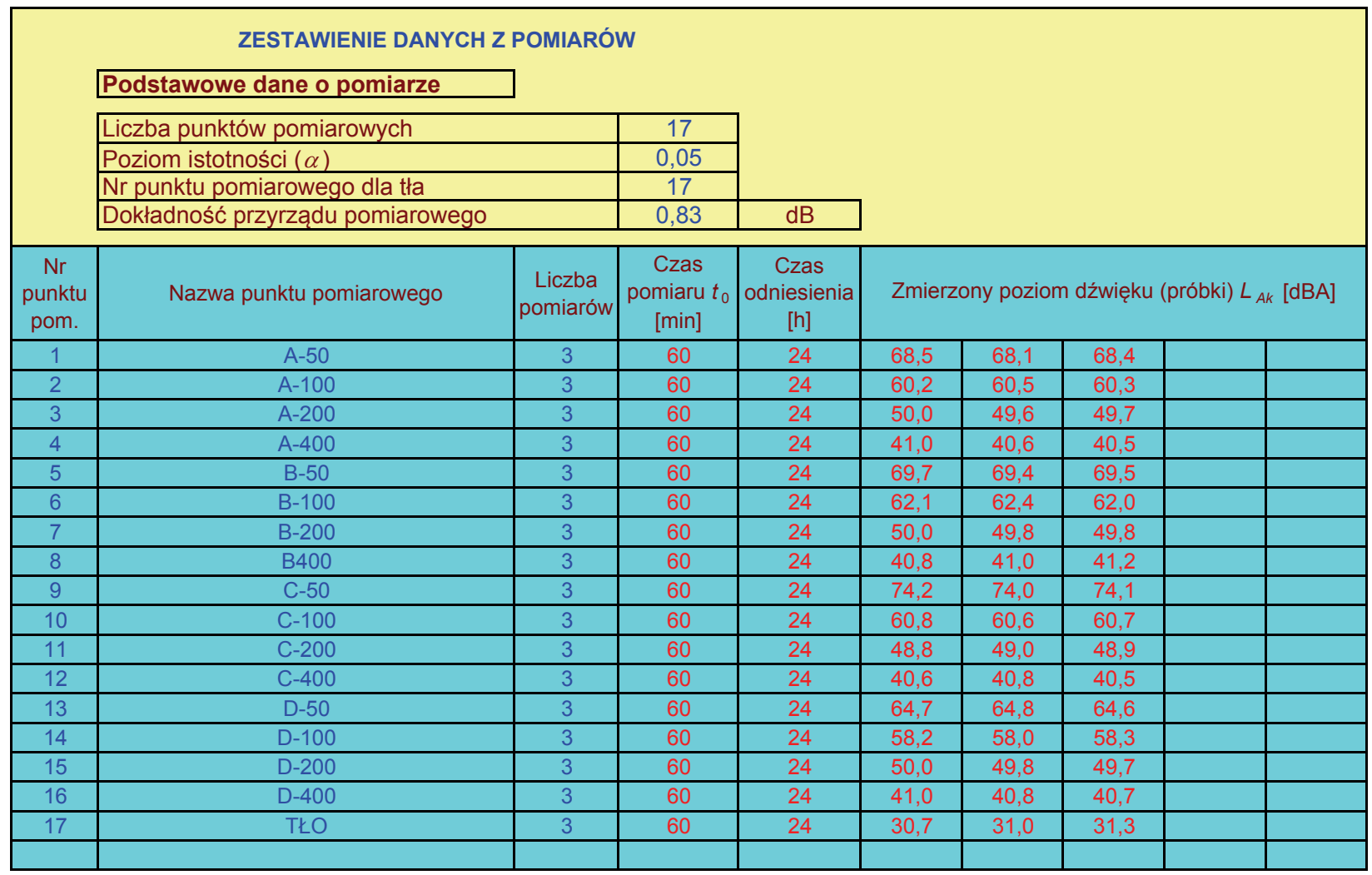

Arkusz „Wyniki”

\begin{tabular}{|c|c|c|c|c|c|c|c|c|c|c|}
\hline $\begin{array}{c}\mathrm{Nr} \\
\text { punktu } \\
\text { pom. }\end{array}$ & $\begin{array}{l}\text { Nazwa punktu } \\
\text { pomiarowego }\end{array}$ & $\begin{array}{l}\text { Liczba } \\
\text { pomiarów }\end{array}$ & $\begin{array}{c}\text { Średni } \\
\text { poziom } \\
\text { dźwięku } \\
L_{\text {Asr }}[\mathrm{dBA}]\end{array}$ & $\begin{array}{c}\text { Poziom } \\
\text { emisji } \\
\text { hałasu } \\
L_{\text {Aek }}[\mathrm{dBa}]\end{array}$ & $\begin{array}{c}\text { Niepewność } \\
\text { rozszerzona } \\
\bigcup_{R, 95}[\mathrm{dBA}]\end{array}$ & 1 & 2 & 3 & 4 & 5 \\
\hline 1 & A-50 & 3 & 68,3 & 68,3 & 999 & 7079458 & 6456542 & 6918310 & & \\
\hline 1 & $A-100$ & 3 & 60,3 & 60,3 & 999 & 1047129 & 1122018 & 1071519 & & \\
\hline 1 & $A-200$ & 3 & 49,8 & 49,7 & 999 & 100000 & 91201 & 93325 & & \\
\hline 1 & $A-400$ & 3 & 40,7 & 40,2 & 999 & 12589 & 11482 & 11220 & & \\
\hline 1 & B-50 & 3 & 69,5 & 69,5 & 999 & 9332543 & 8709636 & 8912509 & & \\
\hline 1 & B-100 & 3 & 62,2 & 62,2 & 999 & 1621810 & 1737801 & 1584893 & & \\
\hline 1 & B-200 & 3 & 49,9 & 49,8 & 999 & 100000 & 95499 & 95499 & & \\
\hline 1 & B400 & 3 & 41,0 & 40,5 & 999 & 12023 & 12589 & 13183 & & \\
\hline 1 & C-50 & 3 & 74,1 & 74,1 & 999 & 26302680 & 25118864 & 25703958 & & \\
\hline 1 & C-100 & 3 & 60,7 & 60,7 & 999 & 1202264 & 1148154 & 1174898 & & \\
\hline 1 & C-200 & 3 & 48,9 & 48,8 & 999 & 75858 & 79433 & 77625 & & \\
\hline 1 & C-400 & 3 & 40,6 & 40,1 & 999 & 11482 & 12023 & 11220 & & \\
\hline 1 & $\mathrm{D}-50$ & 3 & 64,7 & 64,7 & 999 & 2951209 & 3019952 & 2884032 & & \\
\hline 1 & $\mathrm{D}-100$ & 3 & 58,2 & 58,2 & 999 & 660693 & 630957 & 676083 & & \\
\hline 1 & $\mathrm{D}-200$ & 3 & 49,8 & 49,8 & 999 & 100000 & 95499 & 93325 & & \\
\hline 1 & D-400 & 3 & 40,8 & 40,4 & 999 & 12589 & 12023 & 11749 & & \\
\hline & & & & & & & & & & \\
\hline
\end{tabular}

\section{Podsumowanie}

Z przeprowadzonych pomiarów wynika, że w wielu przypadkach poziom hałasu emitowanego przez urządzenia wiertnicze do środowiska przekracza dopuszczalne wartości (podane w odpowiednich regulacjach prawnych), m.in. w strefie zabudowy mieszkaniowej. Pierwszoplanowym środkiem ograniczającym hałas jest uwzględnienie wymagań ochrony przed hałasem na etapie projektowania urządzenia wiertniczego. Stosowanie środków ochrony przeciwdźwiękowej czynnej i biernej przed hałasem wymaga odpowiednich działań producentów i użytkowników urządzeń wiertniczych. Ochrona przeciwdźwiękowa to m.in. wyłożenie powierzchni ścian materiałami i ustrojami dźwiękochłonnymi, wykorzystywanie ekranów 
akustycznych ustawionych wokół hałaśliwego urządzenia lub maszyny roboczej, zastosowanie obudowy izolacyjnej urządzeń, zwłaszcza w rejonach gęsto zaludnionych. Ograniczenie hałasu osiąga się przez zastosowanie w urządzeniach wiertniczych kontenerów z izolacyjnymi ścianami jako pomieszczeń dla napędów spalinowych i sprężarek. W tym kierunku zmierza także użycie cichych układów hamulcowych wyciągu wiertniczego, pokrycie osłonami części napędowej pomp płuczkowych, zastosowanie hydraulicznego systemu manewrowania rurami z ograniczeniem użytkowania wind powietrznych. Wykorzystanie na przykład podkładek amortyzujących, węży antywibracyjnych w instalacji pomp płuczkowych w znacznym stopniu ogranicza rozprzestrzenianie się dźwięków.

Prosimy cytować jako: Nafta-Gaz 2016, nr 2, s. 118-123, DOI: 10.18668/NG.2016.02.07

Artykuł nadesłano do Redakcji 14.10.2015 r. Zatwierdzono do druku 23.12.2015 r.

Artykuł powstał na podstawie pracy statutowej pt. Badanie emisji hałasu urządzeń wiertniczych do środowiska w otoczeniu wiertni zgodnie z wymogami Unii Europejskiej - praca INiG - PIB na zlecenie MNiSW; nr archiwalny: DK-4100-24/15, nr zlecenia: $0024 / \mathrm{KA} / 15 / 01$.

\section{Literatura}

[1] Balawajder Z., Buczek J.: Badania poziomu hałasu emitowanego do środowiska przez urządzenia wiertnicze. Materiały INiG - PIB, 2014-2015.

[2] Urba R., Bednarz S.: Emisja hałasu urzadzeń wiertniczych do środowiska otaczajacego wiertnie. Bezpieczeństwo Pracy i Ochrona Środowiska w Górnictwie 2007, nr 12, s. 15-22.

\section{Akty prawne i normatywne}

[3] Dyrektywa 2002/49/WE Parlamentu Europejskiego i Rady z dnia 25 czerwca 2002 r. odnosząca się do oceny i zarządzania poziomem hałasu w środowisku.

[4] Metodyka referencyjna wykonywania okresowych pomiarów hałasu w środowisku pochodzącego z instalacji lub urządzeń, $\mathrm{z}$ wyjątkiem hałasu impulsowego. Załącznik nr 7 do rozporządzenia Ministra Środowiska z dnia 30 października 2014 r. w sprawie wymagań w zakresie prowadzenia pomiarów wielkości emisji oraz pomiarów ilości pobieranej wody (Dz. U. poz. 1542).
[5] PN-ISO 1996-1 Akustyka. Opis i pomiary hałasu środowiskowego. Część 1. Wielkości podstawowe i procedury oceny, 2006.

[6] PN-ISO 1996-2 Akustyka. Opis i pomiary hałasu środowiskowego. Zbieranie danych dotyczacych sposobu zagospodarowania terenu, 1999.

[7] PN-ISO 1996-3 Akustyka. Opis i pomiary hałasu środowiskowego. Wytyczne dotyczace dopuszczalnych poziomów hałasu, 1999.

[8] PN-N-01341 Hałas środowiskowy. Metody pomiaru i oceny hałasu przemystowego, 2000.

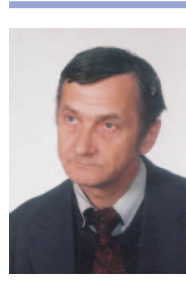

Dr inż. Roman URBA

Kierownik Zakładu Badań Środowiskowych

i Atestacji w Przemyśle Naftowym. Instytut Nafty i Gazu - Państwowy Instytut Badawczy

ul. Lubicz 25 A

31-503 Kraków

E-mail: roman.urba@inig.pl 